\title{
Structural Changes in Deformed Soft Magnetic Ni-Based Metallic Glass
}

\author{
A. Juríková, K. Csach, J. MišKuf \\ Institute of Experimental Physics, Slovak Academy of Sciences \\ Watsonova 47, 04001 Košice, Slovakia \\ AND V. OCELÍK \\ Department of Applied Physics, Materials Science Centre \\ and Netherlands Institute of Metals Research, University of Groningen \\ Nijenborgh 4, NL-9747 AG Groningen, The Netherlands
}

\begin{abstract}
The effects of intensive plastic deformation of the soft magnetic metallic glass $\mathrm{Ni}-\mathrm{Si}-\mathrm{B}$ on the structural relaxation were examined. The enthalpy changes studied by differential scanning calorimetry revealed that the intensive plastic deformation was associated with the partial structural relaxation of the amorphous structure.
\end{abstract}

PACS numbers: 61.43.Dq, 62.20.Hg

\section{Introduction}

Understanding of structural relaxation processes in metallic glasses is important not only for their technical applications but also for knowing the nature of their structure. The combination of high glass-forming ability and good mechanical and soft magnetic properties of the Ni-based amorphous metallic alloys indicates their perspective applications. Structural relaxation is associated with changes in the short-range order within the amorphous structure and it manifests itself by a decrease in the enthalpy and by changes in many structural sensitive physical properties upon thermal treatment, e.g. the Curie temperature $[1,2]$ or magnetoelastic characteristics [3].

Plastic deformation in metallic glasses occurs through the formation of highly localized narrow regions, i.e. shear bands that propagate under adiabatic conditions and the high local heating is observed [4]. In the locally heated and rapid cooled shear band regions a higher amount of free volume should be present. The free volume is one of the most important structural features of amorphous materials. Differential scanning calorimetry (DSC) analysis is the effective method to characterize the structural relaxation closely related to the free volume in the amorphous structure. It is possible to estimate the relative changes in the free volume by measuring the enthalpy changes. In the work we studied the deformation-induced free volume change in the $\mathrm{Ni}-\mathrm{Si}-\mathrm{B}$ amorphous ribbon.

\section{Experimental}

An amorphous metallic alloy of the nominal composition of $\mathrm{Ni}_{77.5} \mathrm{Si}_{7.5} \mathrm{~B}_{15}$ (at.\%) with the thickness of $18.8 \mu \mathrm{m}$ produced at the Institute of Physics of Slovak Academy of Sciences in Bratislava by the melt-spinning method [5] was used in experiments. The amorphous structure of the ribbon was checked by X-ray diffraction. The onset crystallization temperature of the amorphous ribbon, estimated by DSC for the as-quenched sample, is $T_{x}=764 \mathrm{~K}$.

The amorphous ribbon samples were mechanically deformed using an indenter with the tip radius of $1 \mathrm{~mm}$ in such a way that the surface area was covered by impactions. The accumulated deformation was characterized as the total time of repeated impactions of the indenter. In this way the samples with lower and higher (in the ratio 1:5) deformation were obtained. Another piece of the as-quenched amorphous ribbon sample was undergone four subsequent DSC runs for studying the structural relaxation.

The enthalpy changes for the deformed samples as well as for the as-quenched (i.e. undeformed) sample were measured using a Perkin Elmer DSC 7 differential scanning calorimeter up to the temperature of $693 \mathrm{~K}$ at the heating rate of $20 \mathrm{~K} / \mathrm{min}$ followed by cooling to the room temperature with the rate of $200 \mathrm{~K} / \mathrm{min}$. A flowing nitrogen atmosphere was used to protect samples. The heating up to the temperature of $693 \mathrm{~K}$, i.e. about $70 \mathrm{~K}$ below the crystallization temperature, was chosen to prevent the crystallization. The deformed ribbon surface was examined using a JSM-7000F scanning electron microscope.

\section{Results and discussion}

Repeated indenter impactions on the sample surface lead to the plastic deformation of the amorphous ribbon 
through the creation of shear bands. Figure 1a shows the morphology of the lower surface of a deformed Ni-based metallic glass specimen. The deformation region contains a high density of shear bands. In Fig. 1b there is a detailed view of shear bands propagating in different directions. Similar morphology of the deformed surface was observed for other metallic glasses after punch tests $[6,7]$.
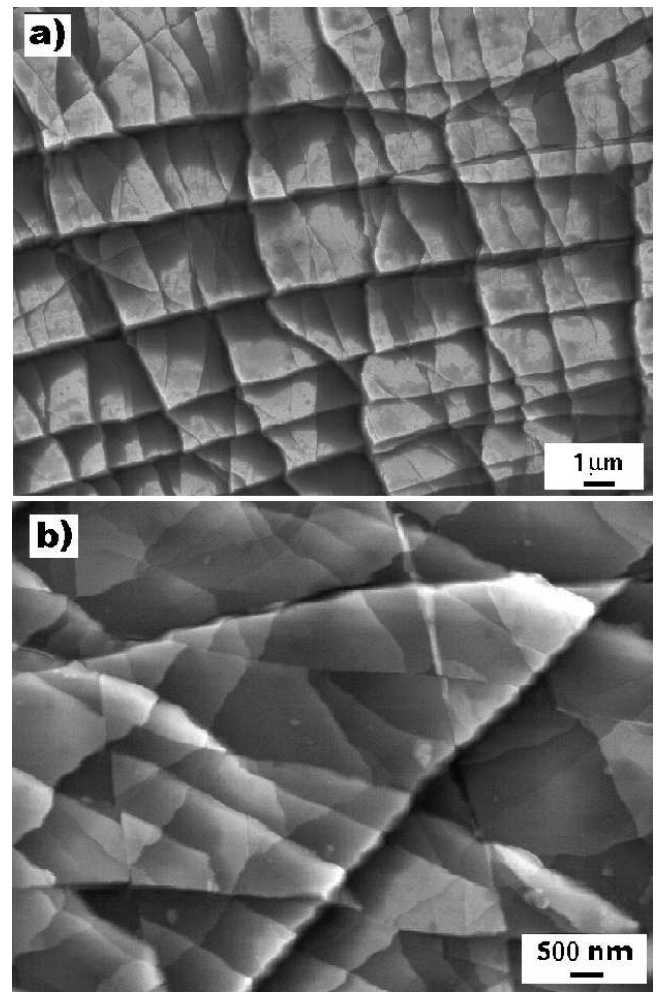

Fig. 1. The morphology of shear bands on the lower surface of a Ni-Si-B metallic glass sample after the deformation (a) and a detailed view of shear bands (b).

Representative DSC scans of the as-quenched sample can be seen in Fig. 2a where DSC traces of four subsequent heating runs of the same sample are presented. The structural relaxation associated with an annihilation of the excess free volume is manifested as an exothermic effect in DSC traces. Figure $2 \mathrm{~b}$ shows DSC traces of the lower and the higher deformed samples. For comparison, the DSC trace of the as-quenched (i.e. undeformed) sample from Fig. 2a is also included.

For characterization of structural changes due to the structural relaxation and the deformation, the total enthalpy changes $\Delta H$ were calculated by integrating the heat flow curves taking the fourth run scan as a baseline. The enthalpy decreases with the structural relaxation from the value of $23.6 \mathrm{~J} / \mathrm{g}$ for the sample in as-quenched state to the value of $0.3 \mathrm{~J} / \mathrm{g}$ for the sample subjected to the third heating run. The enthalpy value for as-quenched sample is in good agreement with the one published for $\mathrm{Cu}$-based amorphous ribbon [8]. The

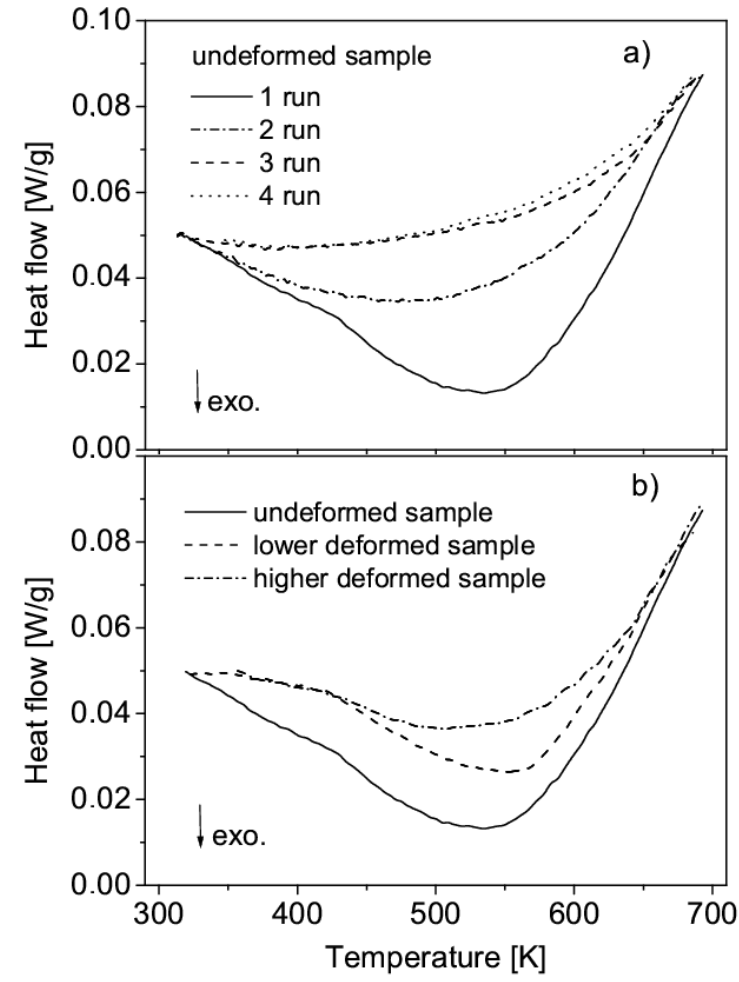

Fig. 2. DSC traces of the $\mathrm{Ni}-\mathrm{Si}-\mathrm{B}$ amorphous ribbon (a) in as-quenched state for four subsequent heating runs and (b) in deformed states.

heat released from the sample subjected to higher deformation $(8.5 \mathrm{~J} / \mathrm{g})$ is smaller than from the one subjected to lower deformation $(13 \mathrm{~J} / \mathrm{g})$.

The free volume theory gives the following enthalpy change dependence on the amount of escaping free volume [9]: $\Delta H=\beta^{\prime} \Delta v_{\mathrm{f}}$, where $\Delta v_{\mathrm{f}}$ is the change of free volume per atomic volume and $\beta^{\prime}$ is a constant and can be interpreted as the formation energy of a vacancy with the magnitude of one atomic volume. The value of $\beta^{\prime}$ was estimated by van den Beukel and Sietsma [9] for Pd-based metallic glasses as $\beta^{\prime}=280 \mathrm{~kJ} / \mathrm{mol}$ that we used for the determining free volume changes in this work. The results from DSC experiments are summarized in Table.

TABLE

Summary of DSC results for Ni-based ribbons in different structural states.

\begin{tabular}{c|c|c|c|c|c}
\hline \hline Sample & \multicolumn{2}{|c|}{ Undeformed } & \multicolumn{2}{c}{ Deformed } \\
state & 1. run & 2. run & 3. run & lower & higher \\
\hline$\Delta H[\mathrm{~J} / \mathrm{g}]$ & 23.6 & 9.1 & 0.3 & 13.0 & 8.5 \\
$\Delta v_{\mathrm{f}}[\%]$ & 0.41 & 0.17 & 0.01 & 0.23 & 0.15
\end{tabular}

In the as-quenched alloy an excess amount of free volume is frozen due to the non-equilibrium processing conditions. During subsequent heating runs to the tempera- 
ture of $693 \mathrm{~K}$ the structural relaxation occurs. Between the third and the fourth run only small energy release was observed, so the sample structure after the fourth heating run is considered as relaxed.

If the free volume increases during intensive plastic deformation through the adiabatic creation of shear bands, DSC measurements should yield higher enthalpy in the deformed glass in comparison with the as-quenched one. However, our experimental results indicate a reduction in the enthalpy and so a reduction in the free volume due to the deformation (see Table). Similar phenomena were also observed for other metallic glasses $[6,10]$. This is contrary to the expectation that the excess free volume is generated during plastic deformation due to temperature rise in shear bands and the appearing of the liquid-like layer [4]. Bhowmick et al. [6] concluded that one of the possible explanations can be the condensation of the excess free volume generated during prior-plastic deformation into nanovoids. We suppose that another mechanism for the structural relaxation during deformation could be also considered. The stress fields near shear bands can cause some atom rearrangements similar to the structural relaxation events. The complete description of this phenomenon needs some additional examinations.

\section{Conclusion}

Contrary to the general expectation, DSC analysis indicates a reduction in the free volume during the localized plastic deformation of the amorphous ribbon. The higher plastic deformation is accumulated, the more relaxed structure of the amorphous alloy can be considered.

\section{Acknowledgments}

The work was supported by the Slovak Grant Agency for Science - VEGA (grant No. 2/0080/08).

\section{References}

[1] J.M. Borrego, C.F. Conde, A. Conde, Mater. Sci. Eng. A 304-306, 491 (2001).

[2] A. Lovas, A. Böhönyey, L.F. Kiss, J. Kováč, P. Németh, Mater. Sci. Eng. A 375-377, 1097 (2004).

[3] A. Bieńkowski, J. Salach, R. Szewczyk, R. Kolano, Acta Phys. Pol. A 113, 87 (2008).

[4] V.Z. Bengus, E.D. Tabachnikova, S.E. Shumilin, Y.I. Golovin, M.V. Makarov, A.A. Shibkov, J. Miškuf, K. Csach, V. Ocelík, Int. J. Rapid Solid. 8, 21 (1993).

[5] P. Duhaj, P. Švec, E. Majková, V. Boháč, I. Maťko, Mater. Sci. Eng. A 133, 662 (1991).

[6] R. Bhowmick, R. Raghavan, K. Chattopadhyay, U. Ramamurty, Acta Mater. 54, 4221 (2006).

[7] Z. Zhang, F. Wu, G. He, J. Eckert, J. Mater. Sci. Technol. 23, 747 (2007).

[8] W.H. Jiang, F.X. Liu, Y.D. Wang, H.F. Zhang, H. Choo, P.K. Liaw, Mater. Sci. Eng. A 430, 350 (2006).

[9] A. van den Beukel, J. Sietsma, Acta Metall. Mater. 38, 383 (1990).

[10] D.J. Safarik, C.M. Cady, R.B. Schwarz, Acta Mater. 53, 2193 (2005). 